\title{
Developing an economic, environmental and agronomic case for the increased use of organic amendments in South Asia
}

David W. Rowlings ${ }^{\text {* }}$, Aguna Liyanage ${ }^{b}$, Jana Kholova c, Shanthi Jagadabhi c , Sudheera M.W. Ranwala ${ }^{\text {d, }}$ and Anthony Whitbread ${ }^{\mathrm{c}}$

a Institute for Future Environments, Queensland University of Technology, Brisbane, QLD 40oo, Australia

$b$ Department of Agriculture Biology, Faculty of Agriculture, University of Ruhuna, Kamburupitiya, 8110o, Sri Lanka

c Innovation Systems for the Drylands, International Cropping Research Institute for the Semi-Arid Tropics

d Department of Plant Science, Faculty of Science, University of Colombo oo3oo, Sri Lanka

* Corresponding author.Email: d.rowlings@qut.edu.au

\section{ABSTRACT}

Aggressive fertilizer subsidies throughout South Asia have led to a rapid increase in the use of synthetic nitrogen fertilizers such as urea at the farm level. While this has been successful in increasing yields, significant yield gaps remain between potential and actual farm yields, while unbalanced or over application of fertilizers potentially damages soil and environmental health. This project examined organic amendment (OA) application in India and Sri Lanka on productivity, soil properties and greenhouse gas emissions. In India, poultry, farm-yard manure and vermi-compost were applied to a paddy rice crop, and the potential benefits followed through to a post-rice chickpea crop. In Sri Lanka, we tested the optimal combination of synthetic nitrogen fertilizer rates when using municipal-waste compost in a multi-year maize-soybean rotation. Results at both trial sites saw an increase in crop yields under OA application; in particular chickpea yields from farm-yard manure and after repeated application of municipal-waste compost. However, all OA treatments increased emissions of the greenhouse gases nitrous oxide and methane due to additional nitrogen or carbon availability. Furthermore, the low nutrient content and relatively high cost of the OA's, particularly the composts, made them uneconomical as nutrient sources compared to conventional fertilizers.

\section{KEYWORDS \\ Composts, Fertilizers, Greenhouse gases, Manures, Nitrogen use efficiency, Organic amendments}

\section{DOI}

https://doi.org/10.30852/sb.2019.780

\section{DATES}

Received: 10 April 2019

Published (online): 30 October 2019

Published (PDF): 4 December 2019

\section{HIGHLIGHTS}

OA increased maize yields by $21 \%$ or fertilizer savings of USD 48 ha $^{-1}$ in urea costs.

" OA increased yields in post-rice chickpeas by up to $1200 \mathrm{~kg} \mathrm{ha}^{-1}$ but also increased greenhouse gases by up to $30 \%$.

» Input costs per $\mathrm{Mg}$ of grain produced were up to 25 times higher using compost.

\section{INTRODUCTION}

South Asia is home to a growing population of over 1.6 billion people, and it is estimated the region will have to double its food production between 2010 and 2050 to match increased demand. To achieve this, both India and Sri Lanka have accorded high priority to the use of fertilizers for achieving self-sufficiency and have implemented substantial subsidy programs, particularly on urea nitrogen $(\mathrm{N})$ fertilizer. Synthetic $\mathrm{N}$ fertilizer input onto farms has increased 8-fold over the last century, including a doubling in South Asia since 1990 (Lu \& Tian, 2017). At the same time, $N$ use efficiencies (NUE) in the
South Asia region, i.e., the amount of applied $\mathrm{N}$ fertilizer that is converted into harvested products, has dropped below 35\% (Luis, Gilles, Bruna, Juliette, \& Josette, 2014), primarily due to excessive application rates linked to heavy fertilizer subsidies. This combination of increasing $\mathrm{N}$ inputs and low NUE is the primary driver for increased losses of reactive $\mathrm{N}$ contributing to a number of environmental problems such as increased emissions of the potent greenhouse gas nitrous oxide $\left(\mathrm{N}_{2} \mathrm{O}\right)$ (Bouwman, Boumans, \& Batjes, 2002).

In this context, considering the vast amounts of organic residues produced in India and Sri Lanka, 
organic soil amendments (OAs), particularly in the form of composts, have been touted as an effective means of replacing or supplementing part of crop synthetic fertilizer requirements with a cheap source of nutrients, while increasing soil productivity and "health", and reducing the environmental costs associated with industrial $\mathrm{N}$ fixation (Ceotto, 2005). While benefits of increased nutrient stocks following $\mathrm{OA}$ application are relatively easy to quantify, and plant nutrient availability less so, OAs have primarily been promoted as a means to maintain or increase "soil health", the intuitive but hard to quantify confluence of optimal soil physical, chemical and biological properties often linked to soil organic matter. Valuing these additional benefits is made even more difficult by the long-term application time frame required to see these benefits (De Rosa et al., 2017), with quantification through longitudinal studies rare.

While many studies have demonstrated the benefits of applying OAs including enhancing both physical and chemical soil properties (Leroy et al., 2008; Quilty \& Cattle, 2011) and soil carbon sequestration (De Rosa et al., 2017), few have critically examined the agronomic, environmental and economic benefits compared directly to equivalent inputs of synthetic fertilizers. Disentangling the additional nutrient benefits from other perceived soil health benefits in these studies is not always possible, making direct comparisons with synthetic fertilizer difficult. The high cost and low nutritional value of some OA products, combined with uncertainty around their capacity to match plant nutrient demand, ensures the use of $\mathrm{OA}$ in farming systems is substantially more complicated than conventional synthetic fertilizer. As such, there is a tendency for farmers to either over apply to match a single nutrient requirement (usually phosphorous) leading to the over application of $\mathrm{N}$, or to apply simply as a "feel good" factor with no clear idea of the return on investment. Adding to this, various local and state governments have implemented schemes promoting activities such as composting, both as a means of reducing the cost of processing municipal wastes, but to also minimize reliance and costs of imported synthetic fertilizer (Bandara, 2008; de LW Samarasinha, Bandara, \& Karunarathna, 2015). For instance, the Sri Lankan governments "Mahinda Chinthana" policy aims to reduce imports of synthetic fertilizers by up to $15 \%$ (MADAS, 2007). These products are promoted to farmers at a substantial premium, costing up to USD $130 \mathrm{Mg}^{-1}$. In Europe and North America, incentives and application rates for OA use largely stem from the need for waste disposal or legislation, driving down the price or encouraging their use. In South Asia however, as with other tropical regions, these drivers from the waste management side are mostly missing, with use focusing solely on improving production, and competing against heavily subsidized synthetic nutrient fertilizers. Low mechanization and increasing local labour costs in these regions are further driving up costs. Ultimately the sustained uptake of OA in tropical agricultural systems depends on improved transparency around the cost-benefits of $\mathrm{OA}$ compared to synthetic fertilizer.

This project examined the impact of two different scenarios of organic amendment use in India and Sri Lanka on productivity, soil properties and greenhouse gas emissions. At the Indian site, three different OAs (poultry manure, farmyard manure and vermi-compost) were applied to a paddy rice crop, and the potential nutritional and soil quality benefits followed through to a post-rice chickpea crop. In Sri Lanka, we tested the optimal combination of synthetic nitrogen fertilizer rates when using municipal-waste compost in a multi-year maize-soybean rotation. Agronomic, economic and environmental outcomes were compared.

\section{METHODOLOGY}

The trial at Matara, Sri Lanka, comprised a municipal-waste compost by fertilizer rate experiment in a maize-soybean cropping rotation for 2.5 years from October 2015 to February 2018. Matara sits in the tropical rainforest climatic zone of the Southern province of Sri Lanka, with an average annual precipitation of $2338 \mathrm{~mm}$ and mean annual temperature of $29.8^{\circ} \mathrm{C}$. The soil at the site is a marginally acidic (pH 6.6) Orthic Acrisols (FAO, $1998)$, comprising of $41 \%$ clay and $28 \%$ sand $(0-20 \mathrm{~cm})$, and is characterized by low-activity clays, low nutrient availability and low base saturation.

The trial had eight treatments in a factorial experiment of two compost rates, zero (oC) and $15 \mathrm{t} \mathrm{ha}^{-1}(+\mathrm{C})$ on dry weight, and four $\mathrm{N}$ rates; Zero $\mathrm{N}(\mathrm{ON})$, Low $\mathrm{N}$ (LN-70 kg N ha-1), Medium N (MN-150 kg N ha $\left.{ }^{-1}\right)$ and High $\mathrm{N}\left(\mathrm{HN}-200 \mathrm{~kg} \mathrm{~N} \mathrm{ha}^{-1}\right)$. The $\mathrm{N}$ application rate $\mathrm{MN}$ was designed to represent a regular farming practice in the region (150 kg N ha-1 for maize and $70 \mathrm{~kg} \mathrm{~N} \mathrm{ha}^{-1}$ for soybean) as recommended by the Department of Agriculture, Sri Lanka. Experimental plots were laid out in a randomized design with four replicate blocks. Compost, produced locally from municipal solid waste in Matara, Sri Lanka, was applied twice ( $15 \mathrm{t} \mathrm{ha}^{-1}$ per application $~ 105 \mathrm{~kg} \mathrm{~N} \mathrm{ha}^{-1}$ ) as dry weight basis at the beginning of each crop in the rotation before planting and incorporated into a depth of $20 \mathrm{~cm}$. Agronomic management followed the local farmer practice in the region. The composition of the compost is shown in Table 1.

In India, kharif (wet season) rice was transplanted into the paddy soil ( $35 \%$ clay, $0.45 \% \mathrm{C}$ ) on 26 July 2017, and harvested on the 24 October. The $6 \mathrm{~m} \mathrm{x} 6 \mathrm{~m}$ 
plots were individually bunded to prevent water and nutrient movement between plots and treatments were randomized within three blocks. Organic amendments selected for the study represented the more common types available in the area and a wide range of nutrient qualities to ensure the study is as relevant as possible to local farmers. OA treatments were applied immediately prior to planting on 26 July 2017 at the higher end of local farmer practice to maximize treatment differences while ensuring economic feasibility. Irrigation was maintained at $2 \mathrm{~cm}$ throughout the rice-growing period with the last irrigation applied one month prior to harvest. Treatments were as follows:

$\mathrm{T}_{1}$ - Farmer practice (Recommended Dose of Fertilizer 120-60-40 kg NPK ha-1)

$\mathrm{T}_{2}-25 \%$ of RDF through Vermi-compost $+75 \% \mathrm{RDF}$ from urea

$\mathrm{T}_{3}-25 \%$ of RDF through Farmyard manure $+75 \%$ $\mathrm{RDF}$ from urea

$\mathrm{T}_{4}-25 \%$ of RDF through Poultry manure $+75 \% \mathrm{RDF}$ from urea

The chickpea fallow crop was planted shortly after rice harvest on 26 October 2017 to capitalize on any residual soil moisture and late kharif rainfall, and was harvested on 24 January 2018. No additional fertilizer was applied. Seeds were directly drilled by hand as per standard farmer practice for the respective crops.

The effects of OA application and different rates of $\mathrm{N}$-fertilizer applications on yield and cumulative GHGs were tested using two-way analysis of variance (ANOVA), and pairwise differences, with an alpha $(\alpha)$ level of 0.05 , identified by the lsmeans package (Lenth, 2016) using the Tukey multiple-comparison test.

\section{RESULTS AND DISCUSSION}

\subsection{Crop yields}

In Sri Lanka, maize grain yield showed a strong response to $\mathrm{N}$ fertilizer rate at the lower application rates, increasing by over $65 \%$ from the oN to the $\mathrm{LN}$ treatment (Figure 1). Additional $\mathrm{N}$ application in the

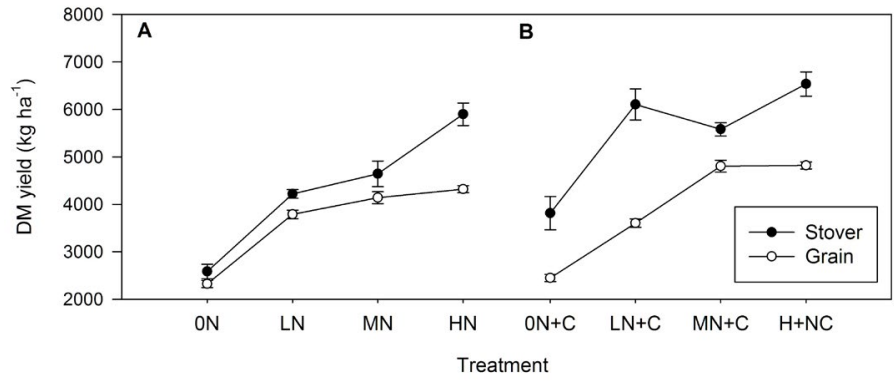

FIGURE 1. Grain and stover yield for the oN, LN (70 $\left.\mathrm{kg} \mathrm{N} \mathrm{ha}^{-1}\right), \mathrm{MN}$ (150 $\left.\mathrm{kg} \mathrm{N} \mathrm{ha}{ }^{-1}\right)$ and $\mathrm{HN}\left(200 \mathrm{~kg} \mathrm{~N} \mathrm{ha}^{-1}\right)$ treatments without (A) and with (B) compost addition (+C) for maize (October 2017 to February 2018) following 3 years of compost application crop at Matara, Sri Lanka.

MN and HN further increased yields though at a slower rate, with yields plateauing and no significant difference being observed between the $\mathrm{MN}$ and $\mathrm{HN}$ rates. A similar pattern was observed in the stover and total AGB, though stover yields continued to increase even at the higher $\mathrm{N}$ rates. Following three years of application, compost addition significantly increased maize yields at the higher $\mathrm{N}$ rates, with the greatest response seen in the MN treatment, which increased total above-ground biomass, grain yield and total $\mathrm{N}$ uptake by $21 \%, 14.5 \%$ and $31 \%$, respectively. Yields from the medium $\mathrm{N}$ application rate with the addition of $15 \mathrm{t}$ of compost $(\mathrm{MN}+\mathrm{C}$, $\left.150 \mathrm{~kg} \mathrm{~N} \mathrm{ha}^{-1}\right)$ were significantly higher $(\mathrm{P}<0.05)$ than the high $\mathrm{N}\left(200 \mathrm{~kg} \mathrm{~N} \mathrm{ha}^{-1}\right)$ rate, which received fertilizer only.

At the International Crops Research Institute for the Semi-Arid Tropics (ICRISAT) based in India, there was no significant difference between stover yields in the kharif rice crop, though a $13 \%$ and $17 \%$ yield penalty $(\mathrm{P}<0.05)$ from farmer practice (FP) associated with the Vermicompost (VC) and Poultry manure (PM), respectively was observed in the grain yield (data not shown). Farmyard manure (FYM) had no impact (negative or positive) on either rice grain or stover production. By contrast, there was a striking increase in the fallow chickpea grain yields in all OA treatments compared to the FP (which failed to set seed), with yields in the PM, VC and FYM increasing by a factor of 5, 10 and 19, respectively (Figure 2), equating to a yield increase of $1,268 \mathrm{~kg} \mathrm{ha}^{-1}$ in the FYM, $634 \mathrm{~kg} \mathrm{ha}^{-1}$ VC, and $286 \mathrm{~kg} \mathrm{ha}^{-1}$ for the PM.

\subsection{Greenhouse gases}

\begin{tabular}{|l|r|r|r|r|r|r|r|}
\hline & $\begin{array}{l}\text { Application rate } \\
\left(\mathrm{Mg} \mathrm{ha}^{-1}\right)\end{array}$ & Total C (\%) & Total N (\%) & $\begin{array}{l}\text { Total N applied } \\
\left(\mathrm{kg} \mathrm{ha}^{-1}\right)\end{array}$ & $\begin{array}{l}\text { Total P applied } \\
\left(\mathrm{kg} \mathrm{ha}^{-1}\right)\end{array}$ & $\begin{array}{l}\text { Total K applied } \\
\left(\mathrm{kg} \mathrm{ha}^{-1}\right)\end{array}$ & $\begin{array}{l}\text { Price } \\
\left(\mathrm{USD} \mathrm{Mg}^{-1}\right)\end{array}$ \\
\hline $\begin{array}{l}\text { Municipal-waste } \\
\text { compost }\end{array}$ & 15 & 19.2 & 0.7 & 105 & - & - \\
\hline Vermi-compost & 5 & 10.1 & 1.1 & 55 & 17.0 & 5110 \\
\hline Farmyard manure & 5 & 24.3 & 2.6 & 130 & 32.8 & 114.2 & $\$ 70$ \\
\hline Poultry manure & 1.5 & 19.0 & 3.2 & 6.0 & 90 & 45.1 & $\$ 48$ \\
\hline
\end{tabular}

TABLE 1. Major compost and manure nutrient parameters for the applied OAs in the trials at Matara, Sri Lanka and ICRISAT, India. 


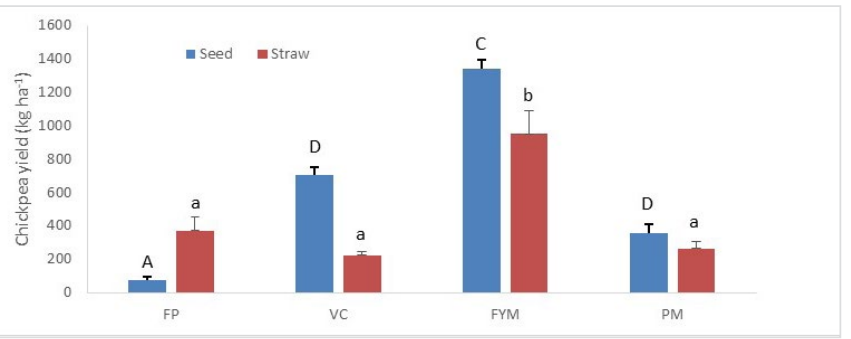

FIGURE 2. Chickpea seed and straw yields for the farmers' practice (FP), Vermi-compost (VC), Farmyard manure (FYM) and Poultry manure (PM) treatments at ICRISAT, India. Letters indicate significant differences between treatments (uppercase $=$ seed, lowercase $=$ straw, $\mathrm{P}<0.05)$.

In both studies, the application of organic amendments increased GHG emissions compared to the fertilizer-only farmer practice. In the maize-soy rotation in Sri Lanka, there was an overall effect of $\mathrm{N}$ rate on annual $\mathrm{N}_{2} \mathrm{O}$ emissions, which increased significantly with the increasing $\mathrm{N}$ fertilizer rate. The application of compost significantly $(\mathrm{P}<0.05)$ increased average annual $\mathrm{N}_{2} \mathrm{O}$ emissions by $39 \%$ in year 1 and $77 \%$ in year 2 at the highest $\mathrm{N}$ fertilizer rate, and $73 \%$ in the $\mathrm{MN}$ rate in year $2(\mathrm{P}=0.063)$. Similar increases were observed in maize in the third year of the experiment (Figure 3). The application of compost increased $\mathrm{CO}_{2}$ emissions only marginally, increasing emissions by $23 \%$ though no significant differences were observed due to high spatial error.

In rice in India, $\mathrm{CH}_{4}$ was by far the most important GHG contributor, accounting for $>95 \%$ of global warming potential (GWP: $\mathrm{N}_{2} \mathrm{O}+\mathrm{CH}_{4}$ expressed in $\mathrm{CO}_{2}{ }^{-}$ equivalents) in the farmers' practice treatment. A similar effect was seen across the OA treatments, except the PM, where the high $\mathrm{N}_{2} \mathrm{O}$ emissions, combined with lower $\mathrm{CH}_{4}$ fluxes, increased the contribution of $\mathrm{N}_{2} \mathrm{O}$ to total GWP to over $50 \%$. Overall, total GWP was lowest in the FP with $135 \mathrm{~kg} \mathrm{CO}_{2}$-eq ha-1 followed closely by PM, increasing to almost $200 \mathrm{~kg} \mathrm{CO}_{2}$-eq ha-1 in the FYM and VC due to higher $\mathrm{CH}_{4}$ emissions.

\subsection{Economic value of organic amendment application}

In Sri Lanka, using a conservative local price of USD 0.28 per $\mathrm{kg}$ of urea, the reduction associated with reducing $\mathrm{N}$ inputs from the $\mathrm{HN}$ rate to the MN rate while achieving comparable yields represents an annual saving of $\sim$ USD 48 per hectare. Alternatively, compost also increased grain yields at the highest $\mathrm{N}$ rate by 0.5 $\mathrm{Mg} \mathrm{ha}^{-1}$, equivalent to USD 114 at local prices, with more value in the stover depending on local markets. The retail price of municipal-waste compost in Sri Lanka has been reported as being between USD $55-140 \mathrm{Mg}^{-1}$. At the application rate of $15 \mathrm{Mg}$ per crop (30 $\mathrm{Mg}$ per year) this corresponds to a per hectare price of USD 1,650 per year, far in excess of the potential savings associated

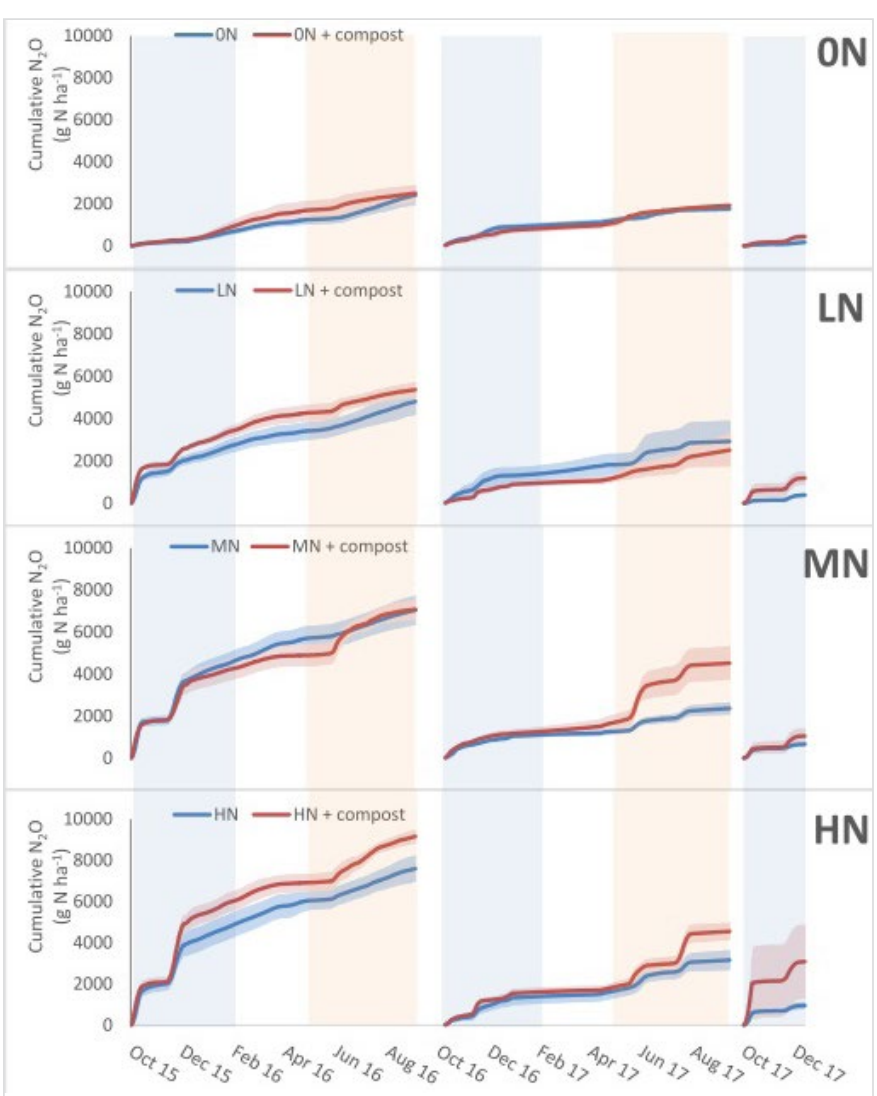

FIGURE 3. Cumulative $\mathrm{N} 2 \mathrm{O}$ fluxes $\left(\mathrm{g} \mathrm{N} \mathrm{ha}^{-1}\right)$ for four $\mathrm{N}$ rates $\mathrm{ON}, \mathrm{LN}, \mathrm{MN}$, HN with compost and no compost during a 2.5-year crop rotation from October 2015 to February 2018 at Matara, Sri Lanka.

with lower urea application or increased yields. At USD 0.29 per kg urea, the value of $\mathrm{N}$ applied in the compost is only USD $126 \mathrm{ha}^{-1}$, and even accounting for other macronutrients ( $\mathrm{P}$ and $\mathrm{K}$ ) can only replace (assuming 100\% availability over time) USD 363 (or USD $12.10 \mathrm{Mg}^{-1}$ ) worth of bagged fertilizer, well short of the USD 1,650 application cost. This is reflected in the input cost per unit of grain and stover produced in maize 3 (Figure 4), which increases from USD 11-29 $\mathrm{Mg}^{-1}$ (grain) for urea as $\mathrm{N}$ rate increases and marginal returns diminish, compared to USD 703-377 $\mathrm{Mg}^{-1}$ for the compost.

Local prices (Hyderabad, India) for the VC, PM and FYM in India are USD 70, 40 and 48 per $\mathrm{Mg}$. In terms of relative value of the macro nutrients added, the PM represented greatest nutrient load at USD $46.33 \mathrm{Mg}^{-1}$ (USD 3.2, 30.8 and 10.3 for $\mathrm{N}, \mathrm{P}$ and $\mathrm{K}$ respectively), followed by FYM at USD $20.30 \mathrm{Mg}^{-1}$ (USD 4.2, 8.2 and 7.9) and VC at USD 9.60 (1.8, 4.3 and 3.5). The significant yield increase in the chickpea resulted in the marginal cost to produce 1 $\mathrm{kg}$ of chickpea of USD 0.19 for FYM, 0.21 for PM and 0.55 for VC. The FYM and PM also contain substantial carbon ( $24 \%$ and $19 \%$ respectively) which may provide additional long-term benefits that are difficult to quantify, while the VC appeared to have a substantial mineral (soil) component with only $10 \%$ carbon.

At a local commodity price of USD 0.87 per $\mathrm{kg}$ of 


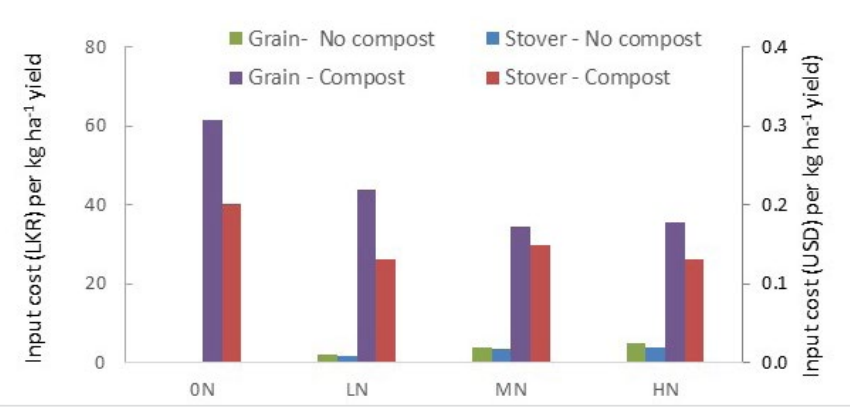

FIGURE 4. Nitrogen input costs in USD per unit of grain or stover produced for the maize 3 crop using urea only or municipal-waste compost combined with urea at different application rates. Urea was priced at USD $0.28 \mathrm{~kg}^{-1}$ and compost at USD $0.06 \mathrm{~kg}^{-1}$.

chickpea, the return on investment (accounting for fertilizer costs only) for $1 \mathrm{~kg}$ of OA was USD 4.60 for FYM, 4.10 and 1.60 for VC. Some of this additional benefit would have been offset in the rice where the $25 \%$ reduction in urea application only reduced costs by USD $10.60 \mathrm{ha}^{-1}$. However, without a urea only comparison in the chickpea it is not possible to compare these returns to synthetic fertilizer costs.

\section{CONCLUSIONS}

In both Sri Lanka and India, significant increases in yields could be demonstrated with both the medium (2.5 years) and short (1 year) term application of organic amendments. However, the high relative cost of OA's compared to synthetic bagged fertilizers requires substantial additional benefits above the value of the nutrients alone to make their use economical. This effect is exacerbated by fertilizer subsidies, which skewer economic benefits even further away from organic amendment use. Additionally, the use of these products in all cases increased GHG emissions through the application of additional N, or through higher carbon inputs, which can stimulate both the production of $\mathrm{N}_{2} \mathrm{O}$ through denitrification, and $\mathrm{CH}_{4}$ through methanogenesis in low carbon soils. As such, for environmental gains to be realized, their use has to be coupled with either reduced use of urea or ammonium-based fertilizers, thus saving GHGs consumed in the production process, with decreased emission intensities (kg GHG emitted per kg of yield produced) or through increased carbon sequestration in soils. Longitudinal studies are required to demonstrate the long-term, cumulative soil benefits of repeated $\mathrm{OA}$ application across a range of management and amendment types, combined with full nutrient and GHG life-cycle assessment of waste streams to ensure pollution swapping does not occur.

\section{ACKNOWLEDGEMENT}

This work was enabled by use of the Central
Analytical Research Facility hosted by the Institute for Future Environments at the Queensland University of Technology.

Special thanks to the University Grants Commission of the Sri Lankan Government for supporting the scholarship and operational costs of the PhD student, Anuga Liyanage.

\section{REFERENCES}

Bandara, N. J. (2008). Municipal solid waste management-The Sri Lankan case. In Proceedings of International Forestry and Environment Symposium.

Bouwman, A. F., Boumans, L. J. M., \& Batjes, N. H. (2002). Emissions of $\mathrm{N}_{2} \mathrm{O}$ and NO from fertilized fields: Summary of available measurement data. Global Biogeochemical Cycles, 16(4).

Ceotto, E. (2005). The issues of energy and carbon cycle: new perspectives for assessing the environmental impact of animal waste utilization. Bioresource Technology, 96(2), 191-196.

de LW Samarasinha, G. G., Bandara, M. A. C. S., \& Karunarathna, A. K. (2015). Municipal Solid Waste Composting: Potentials and Constraints. Hector Kobbekaduwa Agrarian Research and Training Institute.

De Rosa, D., Basso, B., Rowlings, D. W., Scheer, C., Biala, J., \& Grace, P. R. (2017). Can organic amendments support sustainable vegetable production? Agronomy Journal, 109(5), 1856-1869.

Lenth, R. (2016). Least-Squares Means: The R Package lsmeans. Journal of Statistical Software, 69(1), 1-33. doi:http://dx.doi.org/10.18637/jss.v069.io1

Leroy, B. L. M., Herath, H. M. S. K., Sleutel, S., De Neve, S., Gabriels, D., Reheul, D., \& Moens, M. (2008). The quality of exogenous organic matter: short-term effects on soil physical properties and soil organic matter fractions. Soil Use and Management, 24(2), 139-147.

Lu, C., \& Tian, H. (2017). Global nitrogen and phosphorus fertilizer use for agriculture production in the past half century: shifted hot spots and nutrient imbalance. Earth Syst. Sci. Data, 9(1), 181-192.

Luis, L., Gilles, B., Bruna, G., Juliette, A., \& Josette, G. (2014). 50 year trends in nitrogen use efficiency of world cropping systems: the relationship between yield and nitrogen input to cropland. Environmental Research Letters, 9(10), 105011.

MADAS. (2007). National Agriculture Policy of Sri Lanka.

Quilty, J. R., \& Cattle, S. R. (2011). Use and understanding of organic amendments in Australian agriculture: a review. Soil Research, 49(1), 1-26. doi:https://doi. org/10.1071/SR10059 